Demonstração do Valor Adicionado (DVA): Uma Análise da Geração e Distribuição de Riquezas das Empresas Listadas no Índice de Sustentabilidade Empresarial (ISE)-B3

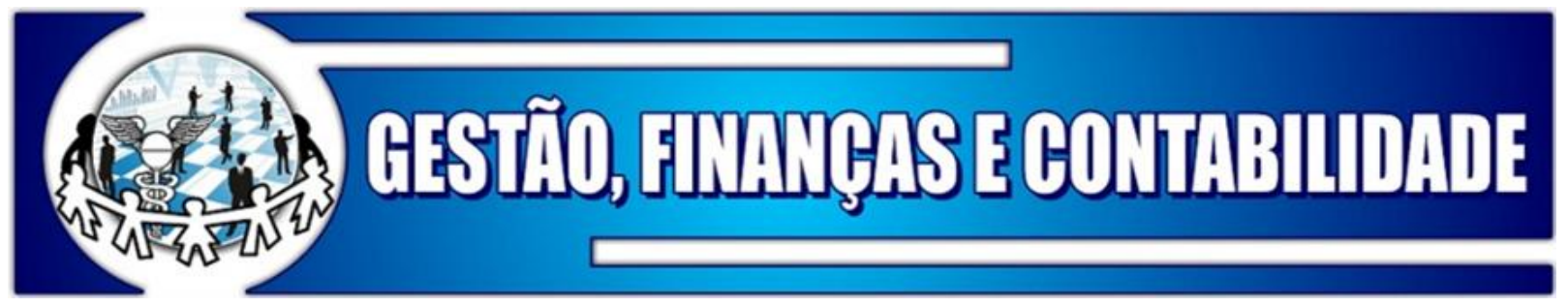

\title{
DEMONSTRAÇÃO DO VALOR ADICIONADO (DVA): UMA ANÁLISE DA GERAÇÃO E DISTRIBUIÇÃO DE RIQUEZAS DAS EMPRESAS LISTADAS NO ÍNDICE DE SUSTENTABILIDADE EMPRESARIAL (ISE)-B3
}

VALUE ADDED STATEMENT (DVA): AN ANALYSIS OF WEALTH GENERATION AND DISTRIBUTION OF COMPANIES LISTED IN THE CORPORATE SUSTAINABILITY INDEX (ISE)-B3

\author{
DECLARACIÓN DE VALOR AGREGADO (DVA): UN ANÁLISIS DE LA \\ GENERACIÓN Y DISTRIBUCIÓN DE RIQUEZA DE LAS EMPRESAS QUE \\ FIGURAN EN EL ÍNDICE DE SOSTENIBILIDAD CORPORATIVA (ISE)-B3
}

\author{
Taís Santos de Sousa \\ Bacharel em Ciências Contábeis pela Universidade de Feira de Santana. \\ E-mail: tais.ssantos1@ hotmail.com \\ Juliano Almeida de Faria \\ Doutor em Engenharia Industrial - Universidade Federal da Bahia \\ E-mail:profjalmeida@gmail.com
}

\section{RESUMO}

Esse trabalho teve como objetivo analisar as DVA publicadas pelas companhias de capital aberto componentes da carteira 2018 do índice ISE-B3. Foram usados indicadores de geração e distribuição de riqueza como variáveis na análise da pesquisa. A análise contemplou a amostra de 30 companhias abertas listadas na carteira de 2018 do ISE e 30 companhias nãoISE listadas na B3 no período de 2014 a 2018. Para analisar a variação dos indicadores utilizou-se o teste estatístico paramétrico t de Student para amostras independentes e o teste Mann-Whitney para amostras não paramétricas. Os resultados obtidos a partir dos testes estatísticos t de Student e Mann-Whitney, em um intervalo de 95\% de confiança, com significância de 0,05 , verificou que as empresas do Grupo ISE e Não ISE apresentam evidências estatísticas similares, ou seja, não apresentaram variação significativa em relação ao período analisado pois o p-value foi superior a $0,05 \mathrm{em}$ todos os casos. Conclui-se assim que o fato das empresas, pertencerem ou não ao Índice de Sustentabilidade Empresarial, não afetou significativamente a DVA dessas empresas, considerando os indicadores utilizados na pesquisa.

PALAVRAS-CHAVE: Demonstração do Valor Adicionado; Índice de Sustentabilidade Empresarial; Indicadores.

\section{ABSTRACT}


Demonstração do Valor Adicionado (DVA): Uma Análise da Geração e Distribuição de Riquezas das Empresas Listadas no Índice de Sustentabilidade Empresarial (ISE)-B3

This study aimed to analyze the DVA published by publicly traded companies in the 2018 portfolio of the ISE-B3 index. Wealth generation and distribution indicators were used as variables in the research analysis. The analysis included the sample of 30 public companies listed in the 2018 ISE portfolio and 30 non-ISE companies listed in B3 from 2014 to 2018. To analyze the variation of the indicators, the Student's t-sample parametric statistical test was used. independent tests and the Mann-Whitney test for nonparametric samples. The results obtained from the Student and Mann-Whitney t-tests, within a 95\% confidence interval, with a significance level of 0.05 , verified that the ISE and Non-ISE Group companies present similar statistical evidences, that is, did not show significant variation in relation to the analyzed period because the p-value was higher than 0.05 in all cases. Thus, the fact that the companies, whether or not they belong to the Corporate Sustainability Index, did not significantly affect the DVA of these companies, considering the indicators used in the research.

KEYWORDS: Statement of Added Value; Corporate Sustainability Index; Indicators.

\section{RESUMEN}

Este estudio tuvo como objetivo analizar el DVA publicado por empresas que cotizan en bolsa en la cartera de 2018 del índice ISE-B3. Los indicadores de generación y distribución de riqueza se utilizaron como variables en el análisis de investigación. El análisis incluyó la muestra de 30 empresas públicas que figuran en la cartera ISE de 2018 y 30 empresas que no son ISE que figuran en B3 de 2014 a 2018. Para analizar la variación de los indicadores, se utilizó la prueba estadística paramétrica de la muestra t de Student. pruebas independientes y la prueba de Mann-Whitney para muestras no paramétricas. Los resultados obtenidos de las pruebas t de Student y Mann-Whitney, dentro de un intervalo de confianza del 95\%, con un nivel de significancia de 0.05, verificaron que las empresas del Grupo ISE y No ISE presentan evidencias estadísticas similares, es decir, no mostró una variación significativa en relación con el período analizado porque el valor $\mathrm{p}$ fue superior a 0,05 en todos los casos. Por lo tanto, el hecho de que las compañías, pertenezcan o no al Índice de Sustentabilidad Corporativa, no afectó significativamente el DVA de estas compañías, considerando los indicadores utilizados en la investigación.

PALABRAS CLAVE: Declaración de valor agregado; Índice de sostenibilidad corporativa; Indicadores.

\section{INTRODUÇÃO}

As empresas são conhecidas por serem agentes econômicos que produzem bens e serviços visando o lucro, porém tem se discutido qual o papel da empresa no âmbito social visto que ela também é um agente social e tem obrigações ocultas para com a sociedade na qual está inserida como realizar ações sociais, conduzir processos produtivos mediante a conservação ambiental, fornecer produtos de qualidade ao mercado, incentivar a formação profissional a fim de obter profissionais qualificados, criação e manutenção de empregos entre outros. Dessa forma, a empresa deve prestar contas à sociedade, sendo essa a postura que se espera de uma empresa responsável socialmente.

O mercado está cada vez mais competitivo e preocupado com o meio ambiente e com questões sociais, em face disto as empresas têm buscado se destacar através de publicações contendo informações que demonstrem não somente o aspecto econômico, mas também a sua 
Demonstração do Valor Adicionado (DVA): Uma Análise da Geração e Distribuição de Riquezas das Empresas Listadas no Índice de Sustentabilidade Empresarial (ISE)-B3

responsabilidade social com meio ao qual está inserida (Silva, 2017). Diante disto, surgiu a Contabilidade Social para levar informações a sociedade, como a Demonstração do Valor Adicionado, um marco na divulgação de informações sociais, buscando tornar as ações das organizações mais transparentes e compromissadas com a responsabilidade social. Por meio da DVA, a empresa divulga informações de natureza social, demonstrando a forma como sua riqueza foi gerada e posteriormente distribuída.

A DVA possibilita a análise dos benefícios que as empresas trazem para a sociedade e segundo Cunha (2002), deve ser entendida como a forma mais competente criada pela entidade para auxiliar na medição da capacidade de geração e distribuição da riqueza em uma entidade. Sendo assim, é possível entender a relação da organização com o ambiente na qual está inserida e sua capacidade contribuir, seja através, dos tributos pagos ao governo, da remuneração paga aos empregados, da remuneração aos capitais de terceiros ou ainda a remuneração destinada aos capitais próprios.

No Brasil a lei 11.638/07 trouxe alterações em relação a publicação das demonstrações contábeis e, dentre essas tornou obrigatória a divulgação da Demonstração do Valor Adicionado, para as companhias de capital aberto, junto as demais demonstrações financeiras publicadas pela entidade ao final de cada exercício tendo como objetivo atender as normas internacionais de contabilidade. As normas referentes a elaboração e apresentação da DVA encontram-se no Pronunciamento Técnico CPC 09.

De Lucca (1998) conclui que a DVA surge como uma importante ferramenta de avalição do conjunto de empresas pertencentes a uma comunidade. O Valor Adicionado calculado através dessa demonstração contábil, representa uma parte relevante da riqueza gerada por um país, oferecendo uma linguagem abrangente que atinge a todos os segmentos da sociedade, como por exemplo, empregados, governo, acionistas e fornecedores

Sendo assim, este estudo buscou compreender a seguinte questão: Como ocorre a geração e a distribuição das riquezas das companhias de capital aberto componentes da carteira 2018 do índice ISE - Índice de Sustentabilidade Empresarial e listadas na B3 (Brasil Bolsa Balcão)?

Esta pesquisa tem como objetivo principal, analisar as DVA's publicadas pelas companhias de capital aberto componentes da carteira 2018 do índice ISE - Índice de Sustentabilidade Empresarial da B3. Para tanto, têm - se como objetivos específicos: i) Medir a geração e a distribuição do valor adicionado aos agentes econômicos que participaram da formação da riqueza, mediante indicadores apresentados na literatura. ii) Avaliar a variação dos índices de atividade das empresas no período de 2014 a 2018 comparando o desempenho na geração e distribuição de riqueza de dois grupos de empresas, as integrantes do ISE e as não integrantes.

A Demonstração do Valor Adicionado configura-se como um importante mecanismo de planejamento e gerenciamento, auxiliando na tomada de decisões (Cunha, 2002). Uma vez que as informações presentes na DVA fornecem dados relevantes quanto à atividade exercida pelas empresas e seus consequentes impactos, observando-se o desempenho social das empresas.

Assim sendo, este estudo da DVA, por meio de análise de indicadores, objetiva avaliar o desempenho das empresas ao longo de 5 (cinco) anos quanto a geração e distribuição de riquezas, com a motivação de confirmar a suposição de formação da carteira ISE, no caso, se as empresas consideradas as mais sustentáveis e com princípios éticos de gestão apresentam resultados superiores na geração e distribuição de valor adicionado em relação a outras empresas. Dessa forma, esse estudo busca contribuir com novas evidências acerca da influência do ISE na performance das empresas no mercado. 
Demonstração do Valor Adicionado (DVA): Uma Análise da Geração e Distribuição de Riquezas das Empresas Listadas no Índice de Sustentabilidade Empresarial (ISE)-B3

Os resultados encontrados sugerem que o fato das empresas, pertencerem ou não ao Índice de Sustentabilidade Empresarial no período analisado, não é refletido significativamente na DVA dessas empresas, considerando os indicadores utilizados na pesquisa. Foram encontradas evidencias que as empresas do Grupo ISE e Não ISE apresentam estatísticas similares pois o p-value foi superior a 0,05 em todos os casos, em um intervalo de confiança de $95 \%$.

Com o intuito facilitar o entendimento do leitor, o artigo está estruturado em cinco seções, incluindo esta introdução que é a primeira delas. A segunda seção contém o referencial teórico, que refere- se as questões que abrangem a DVA, evidenciando sua estrutura e importância para as empresas assim como o impacto do valor adicionado no PIB e a relevância da informação contábil na DVA. A terceira seção trata da metodologia e dos procedimentos para coleta, tabulação e análise dos dados. Na quarta seção estão os resultados da pesquisa e a última seção é dedicada às conclusões do trabalho.

\section{REFERENCIAL TEÓRICO}

\subsection{DEMONSTRAÇÃO DO VALOR ADICIONADO}

A demonstração do Valor Adicionado surgiu em relatos do tesouro americano no Século XVIII, mas foi na Europa que teve seu desenvolvimento impulsionado dada a necessidade de uma demonstração que apurasse o imposto sobre valor agregado, nos países europeus, ganhando destaque no Reino Unido no final dos anos 70, com a publicação do Corporate Report pelo Accounting Standards Steering Committe. Esse relatório recomendava o uso da DVA, abordando o conceito de que os esforços e benefícios gerados pelas empresas são distribuídos aos agentes econômicos. Ainda de acordo com De Luca (1998) surgiu para atender as necessidades de seus colaboradores quanto as informações a respeito de como o a riqueza gerada pela entidade era utilizada.

A DVA apresenta-se como sendo um demonstrativo contábil que as organizações utilizam para apresentar os benefícios oferecidos para sociedade, por exemplo, a utilização da mão de obra da comunidade em que estão inseridas e informar sua contribuição para o meio sócio econômico através da geração de riquezas para a economia, assim como demonstrar de que forma essa riqueza foi distribuída entre os empregados, acionistas, financiadores e o governo. Iudícibus, Gelbcke e Martins (2013), acrescentam que a DVA tem por objetivo apresentar o valor da riqueza gerada pela entidade como resultado do esforço coletivo e sua distribuição entre os componentes que contribuíram para a sua criação.

No âmbito do segmento econômico, através da Demonstração do Valor Adicionado (agregado) é possível perceber a contribuição econômica da entidade para cada segmento com o qual ela se relaciona, constituindo-se no Produto Interno Bruto, produzido pela organização, podendo este ser calculado através da produção, renda e despesas. Marion (2010) destaca que a riqueza gerada pelas empresas pode influenciar diretamente a formação do Produto Interno Bruto (PIB), e por isto tem sido uma demonstração relevante em países emergentes. 
Demonstração do Valor Adicionado (DVA): Uma Análise da Geração e Distribuição de Riquezas das Empresas Listadas no Índice de Sustentabilidade Empresarial (ISE)-B3

Independentemente do país a empresa é componente do sistema produtivo da economia nacional, sendo ela a responsável pela produção de bens e serviços para atender às necessidades da sociedade. Neste contexto, a DVA apresenta a forma como a empresa gerou o valor adicionado, ou seja, riqueza ou, ainda, a renda. Concluindo Oliveira, Rech e Cunha (2015) que o PIB representa a soma dos valores adicionados produzidos por todos os agentes econômicos do país, ou seja, representa a riqueza da nação gerada em um determinado período de tempo. Martins (2013) explica que há uma diferença entre o cálculo econômico e contábil do valor adicionado. Para a economia, o cálculo do PIB se baseia na produção, enquanto que, para a contabilidade, o mesmo se fundamenta na realização da receita.

O Valor Adicionado pode ser descrito no contexto econômico e no contábil sendo estreita a relação entre os seus conceitos, apesar de haver pequenas divergências. No âmbito econômico, é definido como valor adicionado a mensuração das atividades de uma nação, o quanto as operações produtivas agregam de valor aos insumos adquiridos (OLIVEIRA; COELHO, 2014). Na visão contábil, é denominado valor adicionado o resultado fruto das transações econômicas ocorridas dentro dos limites de uma empresa, com base no total das vendas realizadas e não do seu processo produtivo como um todo, podendo ser descrito como a diferença entre as vendas e o total de compras realizadas (NUNES; MIRANDA, 2016).

Uma organização ao demonstrar a geração do seu valor adicionado está expondo a sua capacidade de contratar pessoas, pagar impostos, pagar juros, aluguéis e dividendos aos seus investidores. Quando se utiliza à produção como medição para o produto interno bruto é levado em consideração os valores do armazenamento, manutenção, transporte e comercialização, entre outros, evitando as duplas contagens (DEGENHART; VOGH; HEIN, 2014). Sendo assim segundo Montoto (2018), o valor adicionado é a diferença entre valor de venda e custos dos insumos requeridos para vender um produto. Quanto maior o valor agregado, mais impostos a empresa vai pagar e mais pessoas vai empregar (BRASIL, 2017). Empresas que divulgam a DVA são de interesse para a sociedade e, por isso, sua entrada em alguns países é facilitada pelos governos, por meios de incentivos ficais (MARIN, 2017).

A DVA não era obrigatória no Brasil, até o surgimento da lei $\mathrm{n}^{\circ} 11.638 / 07$ que promoveu alterações na lei 6.404/76, e tornou obrigatória a divulgação dessa demonstração pelas companhias de capital aberto, assim como as outras demonstrações financeiras, devendo ser publicadas ao final de cada ano do exercício. Posteriormente, o Comitê de Pronunciamentos Contábeis (CPC) divulgou o Pronunciamento Técnico CPC 09 Demonstração do Valor Adicionado, regulamentando as normas sobre a divulgação da DVA no Brasil (CPC, 2008). A seguir o quadro 2 mostra as aprovações dos órgãos reguladores quanto a emissão da Demonstração do Valor Adicionado:

Quadro 1 - Aprovações dos Reguladores

\begin{tabular}{|l|l|}
\hline Órgãos Reguladores & Documentos emitidos \\
\hline Comissão de Valores Mobiliários (CVM) & Deliberação 557/08 \\
\hline Conselho Federal de Contabilidade (CFC) & NBC TG 09 \\
\hline Agência Nacional de Transportes Terrestres (ANTT) & Resolução 3.847/3.848 \\
\hline Agência Nacional de Saúde Suplementar (ANS) & Resolução Normativa 322/13 AN I \\
\hline Agência Nacional de Energia Elétrica (ANEEL) & Resolução Normativa 605/14 \\
\hline
\end{tabular}

Fonte: Adaptado Comitê de Pronunciamentos Contábeis (2008) 
Demonstração do Valor Adicionado (DVA): Uma Análise da Geração e Distribuição de Riquezas das Empresas Listadas no Índice de Sustentabilidade Empresarial (ISE)-B3

Parte das informações fornecidas pela DVA podem ser diretamente extraídas da Demonstração do Resultado do Exercício (DRE), sendo as duas elaboradas com base nos dados da contabilidade da empresa e nos princípios contábeis. São de demonstrações que se completam tratando dos mesmos itens, porém com enfoques diferentes, por exemplo, a DRE aborda em sua estrutura juros, salários e outros como despesas ou custos para a geração de receita, entretanto na DVA esses itens referem-se ao modo como os stakeholders receberam sua parcela da riqueza.

O enfoque da DRE é o lucro líquido do exercício, e os mais interessados por essa informação são os sócios, proprietários e acionistas, enquanto que na DVA o foco principal é a geração da riqueza pelas atividades da empresa através de um esforço coletivo de pessoas e a sua distribuição aos agentes que participaram de sua criação, como, os empregados, governo, acionistas, financiadores externos e fornecedores.

Cunha (2002, p.16), discorre sobre a importância da DVA da seguinte forma:

A Demonstração do Valor Adicionado representa um novo rumo em comparação
com as Demonstrações Contábeis tradicionais, pois enquanto estas têm como foco
principal de preocupação a evidenciação das informações sobre o lucro e sua forma
de apuração, para os investidores, aquela mostra, além do lucro dos investidores, a
quem pertence a outra parte da riqueza gerada pela empresa, refletindo, ainda, uma
preocupação empresarial que é nova, e baseada na responsabilidade social, a
remuneração dos fatores de produção que ajudaram a formar a riqueza da
organização.

Dessa forma, é possível concluir que a DVA possa ser utilizada para a análise de investimentos, concessão de financiamento, subsídios governamentais, avaliar a instalação de empresas multinacionais no país, entre outros. Dentre suas características consiste em ser apresentada de forma comparativa seus dados, divulgando simultaneamente as informações referentes ao ano atual e anterior dado o detalhamento de seus dados.

\subsection{VALUE RELEVANCE DA INFORMAÇÃO CONTÁBIL NA DVA}

No Brasil, o CPC 00 (Pronunciamento Conceitual Básico), explica que relevância é quando as informações contábeis presentes nas demonstrações podem influenciar as decisões econômicas dos usuários, contribuindo para o entendimento e avaliação do impacto de eventos passados, presentes ou futuros, confirmando ou corrigindo as suas avaliações anteriores. Dentre as principais características qualitativas da informação contábil útil, está a da relevância e a representação fidedigna. As demonstrações contábeis são elaboradas e apresentadas para os usuários externos em geral, com objetivo de fornecer informações que sejam úteis na tomada de decisões econômicas e nas avaliações por parte desses usuários (CPC 00, 2011).

A informação contábil é vista como um instrumento fundamental na tomada de decisões aos seus usuários, inclusive para os que analisam os investimentos no mercado de ações (MARQUES, SANTOS, e LEMES, 2014). O papel da informação contábil nos mercados financeiros é um dos temas que mais possuem pesquisas na área contábil, visto que de maneira geral ele é um dos principais usuários da informação contábil, por meio de analistas, corretoras, investidores, bancos, entre outros.

De acordo com Machado (2015), estudos voltados à value relevance utilizam o mercado financeiro como plataforma para experimentos de associação entre a relevância da informação contábil e a variação de valores do ativo. Tendo como objetivo medir a eficiência das informações contábeis para os investidores com o propósito de formação do preço das 
Demonstração do Valor Adicionado (DVA): Uma Análise da Geração e Distribuição de Riquezas das Empresas Listadas no Índice de Sustentabilidade Empresarial (ISE)-B3

ações. Uma informação contábil é relevante ou confiável se ela reflete a tempestividade da informação que é repassada aos usuários no valor da ação. De tal forma o value relevance da informação contábil poderia ser avaliado pela resposta nos preços de mercado das ações quando as informações contábeis são publicadas, ou pela capacidade de explicar as variações no preço de mercado destas ações segundo Rodrigues, Elias e Campos (2014).

É possível perceber que a value relevance da informação contábil está intimamente ligada a diversos fatores relacionados à qualidade da informação contábil, entre eles, a capacidade para influenciar na tomada de decisão dos investidores. Neste estudo, foi avaliado a relevância da DVA e sua capacidade de evidenciar aos usuários a capacidade uma empresa de gerar e distribuir riquezas.

Barros (2013) evidencia a relevância da DVA, relacionando o preço das ações com o valor adicionado líquido a distribuir, de 2000 a 2009, para uma amostra de 642 empresas pertencentes a B3. O autor apontou que as informações apresentadas na DVA são relevantes para os diferentes níveis de usuários. Enquanto Stanzani (2016) verificou a importância da DVA para uma amostra de 62 empresas listadas na B3, de 2010 a 2012, e confirmou a relevância dessa demonstração para esclarecer a variação no retorno das ações e para o mercado financeiro.

Em outro estudo, Machado (2015) mostrou a relevância da DVA na explicação do retorno das ações e que a riqueza criada por ação representa melhor a capacidade de explicar esse retorno, pois os usuários esperam que a empresa crie riquezas que garantam o acesso futuro e não só a remuneração do capital próprio. Os investidores têm a necessidade de informações complementares para sua tomada de decisão.

Em estudos anteriores é possível perceber que as pesquisas sobre value relevance inclinam -se a verificar a relevância do lucro líquido e do patrimônio líquido, ambos aspectos contábeis que esclarecem apenas uma pequena parte do preço da ação. Em acréscimo, ao incluir variáveis pertinentes aos interessados na situação de uma companhia, alguns estudos concluíram que o nível de evidenciação possui relevância para explicar uma parte do preço da ação. Esses resultados em relação as pessoas interessadas na situação de uma empresa possibilitam os estudos nessa área, buscando fornecer mais evidências acerca desse fato. A DVA pode apresentar informações em relação à conduta da empresa diante da governança corporativa e dos interesses de usuários dessa informação.

\section{METODOLOGIA}

Esse estudo é classificado como descritivo, segundo Gil (2002), pois seu objetivo principal é descrever, analisar e identificar as características de uma população ou fenômeno estabelecendo relações entre as variáveis. São descritos os dados informados nas Demonstrações do Valor Adicionado quanto a destinação da riqueza das companhias analisadas da carteira 2018 do ISE.

Quanto aos procedimentos, é um trabalho documental, o qual analisa a DVA das companhias pertencentes ao Índice de Sustentabilidade Empresarial carteira de 2018, além de utilizar como fonte primária e secundária, artigos e relatórios divulgados em revista, instruções normativas referentes aos relatórios da DVA, publicações de estudiosos do assunto e periódicos especializados. Silva (2003) explica que a pesquisa documental utiliza materiais que estão dispersos e não receberam nenhum tratamento analítico podendo ser tratado conforme o objetivo da pesquisa. 
Demonstração do Valor Adicionado (DVA): Uma Análise da Geração e Distribuição de Riquezas das Empresas Listadas no Índice de Sustentabilidade Empresarial (ISE)-B3

A abordagem dessa pesquisa esteve apoiada nas perspectivas quali-quantitativa, visto que ambas trabalham simultaneamente, de forma sistêmica e complementar de modo que possa propiciar uma interpretação mais ampla da realidade pesquisada. Conforme Giddens (2012) a pesquisa pode ser feita pelo método misto quantitativo e qualitativo de modo a obter uma compreensão e explicação mais ampla do tema estudado.

No âmbito quantitativo, a pesquisa utiliza instrumentos quantitativos tanto na coleta, quanto no tratamento dos dados, segundo Beuren (2006). É uma forma de interpretar os dados apresentados nas demonstrações, buscando decompor esses demonstrativos para se obter informações mais analíticas. E no qualitativo segundo Gerhardt e Silveira (2009), a pesquisa não se preocupa com representatividade numérica, mas, sim, com o aprofundamento da compreensão de um grupo social, de uma organização, etc. Neste caso, esse trabalho, visa avaliar o desempenho das empresas listadas na carteira ISE - 2018, por meio de indicadores, no período de 2014 a 2018 comparando o desempenho das empresas listadas nessa carteira com as empresas não integrantes desse índice e listadas na Bovespa.

O estudo utilizou como amostra as 30 companhias abertas listadas na carteira de 2018 do Índice de Sustentabilidade Empresarial - ISE e 30 companhias não- ISE listadas na B3, operantes nos mesmos setores das empresas listadas no ISE, totalizando 60 empresas, sendo utilizado as demonstrações financeiras anuais, no período de 2014 a 2018 visando a comparação dessas empresas frente ao seu desempenho nos indicadores de geração e distribuição de riqueza do valor adicionado. O quadro 3 a seguir apresenta as empresas pertencentes a carteira ISE 2018:

Quadro 2 - Carteira ISE 2018

\begin{tabular}{|c|c|c|c|c|c|}
\hline AES Tiete & CCR & CPFL & Engie & Klabin & Natura \\
\hline B2W & Celesc & Duratex & Fibria & Light & Santander \\
\hline Banco do Brasil & Cemig & Ecorodovias & Fleury & Lojas Americanas & Telefônica \\
\hline Bradesco & Cielo & EDP & Itaú Unibanco & Lojas Renner & Tim \\
\hline Braskem & Copel & Eletropaulo & Itaúsa & MRV & Weg \\
\hline
\end{tabular}

Fonte: Bolsa, Brasil e Balcão (B3).

As empresas pertencentes a carteira 2018 do ISE representam 12 setores de atuação dentre os quais: bens industriais/ transporte; bens industriais/ máquinas e equipamentos; consumo cíclico/ comércio; consumo não cíclico / processo pessoal Limpeza; consumo cíclico/ construção civil; financeiro; materiais básicos/madeira e papel; materiais básicos/ químicos; saúde e telecomunicação. Com base nesses setores foram escolhidas as empresas Não - ISE conforme o quadro 4 abaixo:

Quadro 3 - Empresas Não- ISE

\begin{tabular}{|c|c|c|c|c|c|}
\hline Ambev & CVC & Equatorial & Kroton & Pão de açúcar & Taesa \\
\hline Azul & Cyrela Realt & Gerdau & Localiza & Qualicorp & Ultrapar \\
\hline Br Malls & Eletrobras & Gol & Magazine Luiza & Rumo S.A & Usiminas \\
\hline BRF & Embraer & Iguatemi & Marfrig & Smiles & Vale \\
\hline Cosan & $\begin{array}{c}\text { Energias do } \\
\text { Brasil }\end{array}$ & JBS & Multiplan & Suzano S.A & Viavarejo \\
\hline
\end{tabular}

Fonte: Bolsa, Brasil e Balcão (B3).

Os dados utilizados foram coletados a partir do site da B3, considerando as demonstrações financeiras divulgadas pelas empresas. Os valores coletados foram colocados 
Demonstração do Valor Adicionado (DVA): Uma Análise da Geração e Distribuição de Riquezas das Empresas Listadas no Índice de Sustentabilidade Empresarial (ISE)-B3

em planilhas detalhadas por ano, no programa Microsoft Excel, contendo os valores do Valor Adicionado, Receita, Ativo, Patrimônio Líquido, Pessoal, Governo e Lucros/Prejuízos Retidos, sendo esses dados utilizados no cálculo do conjunto de indicadores fornecidos pela literatura contábil apresentados a seguir no Quadro 4, para uma análise comparativa do desempenho dessas empresas integrantes do ISE e não integrantes do ISE. Souza (2015), explica que os indicadores elaborados a partir da DVA são bons avaliadores, pois permite que a riqueza da empresa seja analisada desde a sua geração até a sua distribuição aos demais membros da sociedade.

Quadro 4 - Indicadores de análise da DVA

\begin{tabular}{|c|c|c|}
\hline Indicadores & Descrição & Fórmulas \\
\hline \multirow{7}{*}{$\begin{array}{l}\text { Indicadores de } \\
\text { Geração de } \\
\text { Riqueza }\end{array}$} & Potencial de Retenção de Receita & \multirow{4}{*}{ PPLGR $=$ Valor Adicionado } \\
\hline & & \\
\hline & & \\
\hline & \multirow{2}{*}{$\begin{array}{l}\text { Potencial do Patrimônio Líquido em } \\
\text { Gerar Receita }\end{array}$} & \\
\hline & & PPLGR $=\frac{\text { Patrimônio Líquiào }}{\text { Pán }}$ \\
\hline & Potencial do Ativo em Gerar Riqueza & \multirow{2}{*}{$P A G R=\frac{\text { Valor Adicionado }}{\text { Pato }}$} \\
\hline & & \\
\hline \multirow{6}{*}{$\begin{array}{l}\text { Indicadores de } \\
\text { Distribuição de } \\
\text { Riqueza }\end{array}$} & Participação dos Empregados no Valor & Pessoal \\
\hline & Adicionado & FLAlor Adicionado \\
\hline & Participação dos Governo no Valor & $P G V A=\frac{\text { Governo }}{}$ \\
\hline & Adicionado & Valor Adicionalo \\
\hline & Grau de Retenção do Valor Adicionado & \multirow{2}{*}{$G R V A=\frac{L / P \text { Retialo }}{\text { Valor Aatcionado }}$} \\
\hline & & \\
\hline
\end{tabular}

Fonte: Adaptado Oliveira e Coelho (2014); Souza (2015).

Os indicadores são conceituados da seguinte forma segundo Oliveira e Coelho (2014) e Souza (2015): O PAGR mostra a capacidade do ativo total em contribuir para a geração de riquezas; PPLGR mostra a capacidade do patrimônio líquido da empresa em contribuir para a geração de riquezas; PRR mostra quanto das receitas fica retido na entidade e pode ser agregado como valor adicionado; PEVA evidencia quanto do valor adicionado gerado pela empresa está destinado à sua força de trabalho; PGVA demonstra a contribuição da empresa a sociedade por meio do pagamento de tributos; GRVA mostra quanto do valor adicionado ficou retido na empresa, na forma de reservas ou prejuízos acumulados.

\section{RESULTADOS E DISCUSSÃO}

Inicialmente, realizou-se o cálculo da média para os indicadores de geração de riqueza e estatística descritiva para os indicadores de distribuição das empresas ISE e Não ISE realizando-se uma comparação quanto ao desempenho dessas entidades entre o período 2014 a 2018 resultando nos seguintes resultados obtidos:

Tabela 1 - Indicadores de Geração de Riqueza

\begin{tabular}{c|c|c|c|c|c|c}
\hline Indicadores & Grupos & $\mathbf{2 0 1 4}$ & $\mathbf{2 0 1 5}$ & $\mathbf{2 0 1 6}$ & $\mathbf{2 0 1 7}$ & $\mathbf{2 0 1 8}$ \\
\hline \multirow{2}{*}{ PAGR } & ISE & 0,28 & 0,31 & 0,29 & 0,29 & 0,29 \\
\cline { 2 - 7 } & NÃO - ISE & 0,21 & 0,15 & 0,18 & 0,16 & 0,18 \\
\hline
\end{tabular}


Sousa e Faria (2018)

Demonstração do Valor Adicionado (DVA): Uma Análise da Geração e Distribuição de Riquezas das Empresas Listadas no Índice de Sustentabilidade Empresarial (ISE)-B3

\begin{tabular}{c|c|c|c|c|c|c}
\hline \multirow{2}{*}{ PPLGR } & ISE & 0,69 & 0,98 & 0,82 & 0,81 & 0,74 \\
\cline { 2 - 7 } & NÃO - ISE & 0,20 & 0,61 & 0,61 & 0,42 & 0,84 \\
\hline \multirow{2}{*}{ PRR } & ISE & 5,50 & 0,98 & 0,82 & 0,81 & 0,74 \\
\cline { 2 - 7 } & NÃO - ISE & $-1,58$ & 1,69 & $-0,79$ & 2,30 & $-1,84$ \\
\hline
\end{tabular}

Fonte: Dados da Pesquisa

Pode- se constatar que, no grupo pertencente ao ISE, o potencial do ativo em gerar riqueza girou em torno 0,29 ao longo dos cinco anos e apresentou desempenho superior às empresas, indicando que o ativo gerou percentual maior de valor adicionado nas empresas pertencentes ao ISE. Quanto ao PPLGR as empresas ISE apresentaram um aumento entre 2014 e 2015 de 0,69 para 0,98, porém, obtiveram uma redução de 0,82 em 2016 para 0,74 em 2018, em contrapartida apesar das empresas NÃO - ISE apresentarem um crescimento ao longo dos cinco anos indo de 0,20 para 0,84 as empresas ISE no geral se mantiveram superiores em relação a capacidade do patrimônio líquido de gerar riquezas.

O PRR, potencial de retenção de receita, tem- se reduzido gradualmente nos cinco anos, de 5,50 em 2014 para 0,74 em 2018, embora continue com o maior percentual de retenção. As empresas Não -ISE tiveram oscilações exibindo resultados positivos em 2015 e 2017 e negativos nos outros anos, esses números negativos evidenciam que as empresas não conseguiram obter as receitas necessárias para gerar riquezas chegando até a apresentar receitas negativas como foi o caso da Cosan em 2018 que apresentou - R\$ 17.728,00 em 2018, da Cyrela Realt em 2016, com -R $\$ 4.552,000$ e da Equatorial em 2014 exibindo $\mathrm{R} \$ 3,320,00$.

A Tabela 2 apresenta os resultados da estatística descritiva da participação dos empregados no valor adicionado:

Tabela 2 - Estatística Descritiva do PEVA

\begin{tabular}{l|l|l|l|l|l|l|l|l|l}
\hline Ano & Grupo & Média & Mediana & Variância & $\begin{array}{l}\text { Desvio } \\
\text { Padrão }\end{array}$ & Mínimo & Máximo & Amplitude & Assimetria \\
\hline \multirow{2}{*}{2014} & ISE & 0,16 & 0,11 & 0,02 & 0,14 & 0,00 & 0,48 & 0,47 & 0,98 \\
\cline { 2 - 10 } & $\begin{array}{l}\text { NÃO - } \\
\text { ISE }\end{array}$ & 0,13 & 0,11 & 0,06 & 0,24 & $-0,89$ & 0,50 & 1,39 & $-2,43$ \\
\hline \multirow{2}{*}{2015} & ISE & 0,16 & 0,09 & 0,03 & 0,16 & 0,00 & 0,51 & 0,51 & 0,95 \\
\cline { 2 - 10 } & $\begin{array}{l}\text { NÃO - } \\
\text { ISE }\end{array}$ & 0,24 & 0,11 & 0,19 & 0,43 & $-0,33$ & 2,19 & 2,52 & 3,34 \\
\hline \multirow{2}{*}{2016} & ISE & 0,21 & 0,12 & 0,11 & 0,34 & $-0,11$ & 1,81 & 1,92 & 3,92 \\
\cline { 2 - 10 } & $\begin{array}{l}\text { NÃO - } \\
\text { ISE }\end{array}$ & 0,10 & 0,08 & 0,13 & 0,36 & $-1,59$ & 0,59 & 2,18 & $-3,55$ \\
\hline \multirow{2}{*}{2017} & ISE & 0,17 & 0,11 & 0,02 & 0,14 & 0,00 & 0,44 & 0,44 & 0,75 \\
\cline { 2 - 9 } & $\begin{array}{l}\text { NÃO - } \\
\text { ISE }\end{array}$ & 0,21 & 0,16 & 0,04 & 0,19 & 0,00 & 0,61 & 0,61 & 0,83 \\
\hline \multirow{2}{*}{2018} & ISE & 0,15 & 0,11 & 0,02 & 0,13 & 0,00 & 0,42 & 0,42 & 0,77 \\
\cline { 2 - 8 } & $\begin{array}{l}\text { NÃO - } \\
\text { ISE }\end{array}$ & 0,17 & 0,08 & 0,04 & 0,20 & $-0,01$ & 0,73 & 0,75 & 1,60 \\
\hline
\end{tabular}

Fonte: Dados da Pesquisa. 
Demonstração do Valor Adicionado (DVA): Uma Análise da Geração e Distribuição de Riquezas das Empresas Listadas no Índice de Sustentabilidade Empresarial (ISE)-B3

Segundo Cunha (2002) a preocupação empresarial é nova, e baseada na responsabilidade social, a remuneração dos fatores de produção como os empregados que ajudaram a formar a riqueza da organização. Em relação à média do PEVA, quanto do valor adicionado gerado pela empresa está destinado à sua força de trabalho anual, as empresas do grupo ISE apresentaram uma média superior à do grupo Não ISE apenas nos anos de $2014 \mathrm{e}$ 2016, ficando abaixo da média nos demais anos. O ano de 2016 foi o que apresentou a maior diferença em relação aos grupos, onde o ISE teve uma média de 0,21 , enquanto que o Não ISE apresentou 0,10 .

A mediana das empresas ISE girou em torno de 0,11 nos cinco anos, apresentando superioridade nos anos de 2016 e 2018 e sendo inferior as empresas Não - ISE em 2015 e 2017, sendo que em 2014 ambas obtiveram a mesma mediana de 0,11. As empresas Não - ISE apresentaram uma variação maior em relação as empresas pertencentes a carteira do ISE, obtendo a melhor mediana dentre todas as empresas analisadas 0,16 no ano de 2017 e a pior mediana nesses cinco anos 0,08 no ano de 2018, demonstrando instabilidade ao longo dos anos.

No que tange a variância e o desvio padrão, as empresas estudadas em ambos os grupos apresentaram oscilações parecidas. Em um primeiro momento as empresas ISE apresentaram crescimento de 2014 a 2016, quanto a variância as empresas ISE chegaram a obter seu melhor resultado 0,11 em 2016 e no que se refere ao desvio padrão 0,34 em 2016, enquanto as Não - ISE tiveram um crescimento somente nos dois primeiros anos. Posteriormente ambos os grupos demonstraram decréscimo tanto na variância quanto no desvio padrão em comparação aos anos anteriores, apesar disso em ambas as estatísticas analisadas as empresas do Grupo Não - ISE apresentavam valores superiores às do Grupo ISE durante os cinco anos.

Os menores mínimos foram apresentados pelo grupo Não - ISE durante os anos estudados, sendo que em 2017 tanto o grupo ISE quanto o grupo Não - ISE apresentou 0,00 em relação ao mínimo. Enquanto que os maiores máximos com exceção do ano de 2015, pertencem ao grupo Não - ISE. No quesito valores o menor mínimo foi - 1,59 no ano de 2016 e o maior máximo foi 2,19 no ano de 2015 .

A amplitude das empresas Não - ISE foi maior que as das empresas ISE, em todos os anos estudados, sendo a maior amplitude 2,52 em 2015. A melhor assimetria foi apresentada pelo grupo ISE 3,92 em 2016, enquanto as empresas do grupo Não - ISE apresentaram assimetrias negativas -2,43 em 2014 e $-3,55$ em 2016.

Em seguida apresenta-se os resultados do PGVA, participação do governo no valor adicionado:

Tabela 3 - Estatística Descritiva do PGVA

\begin{tabular}{l|l|l|l|l|l|l|l|l|l}
\hline Ano & Grupo & Média & Mediana & Variância & $\begin{array}{l}\text { Desvio } \\
\text { Padrão }\end{array}$ & Mínimo & Máximo & Amplitude & Assimetria \\
\hline \multirow{2}{*}{2014} & ISE & 0,22 & 0,20 & 0,04 & 0,21 & $-0,03$ & 0,72 & 0,75 & 0,85 \\
\cline { 2 - 9 } & $\begin{array}{l}\text { NÃO - } \\
\text { ISE }\end{array}$ & 0,08 & 0,11 & 0,05 & 0,22 & $-0,76$ & 0,39 & 1,15 & $-2,02$ \\
\hline 2015 & ISE & 0,16 & 0,08 & 0,06 & 0,24 & $-0,14$ & 0,84 & 0,99 & 1,46 \\
\cline { 2 - 10 } & $\begin{array}{l}\text { NÃO - } \\
\text { ISE }\end{array}$ & 0,13 & 0,14 & 0,09 & 0,30 & $-0,95$ & 1,11 & 2,06 & $-0,37$ \\
\hline \multirow{2}{*}{2016} & ISE & 0,24 & 0,21 & 0,07 & 0,26 & $-0,44$ & 0,87 & 1,31 & 0,29 \\
\cline { 2 - 9 } & $\begin{array}{l}\text { NÃO - } \\
\text { ISE }\end{array}$ & $-0,70$ & 0,11 & 20,97 & 4,58 & $-24,92$ & 0,58 & 25,50 & $-5,46$ \\
\hline \multirow{2}{*}{2017} & ISE & 0,23 & 0,21 & 0,04 & 0,21 & $-0,01$ & 0,83 & 0,84 & 1,33 \\
\cline { 2 - 8 } & $\begin{array}{l}\text { NÃO - } \\
\text { ISE }\end{array}$ & 0,21 & 0,15 & 0,17 & 0,41 & $-0,39$ & 2,20 & 2,59 & 4,16 \\
\hline
\end{tabular}


Demonstração do Valor Adicionado (DVA): Uma Análise da Geração e Distribuição de Riquezas das Empresas Listadas no Índice de Sustentabilidade Empresarial (ISE)-B3

\begin{tabular}{l|l|l|l|l|l|l|l|l|l}
\hline 2018 & ISE & 0,21 & 0,17 & 0,05 & 0,21 & $-0,04$ & 0,82 & 0,86 & 1,52 \\
\cline { 2 - 9 } & $\begin{array}{l}\text { NÃO - } \\
\text { ISE }\end{array}$ & 0,22 & 0,14 & 0,22 & 0,47 & $-0,04$ & 2,59 & 2,63 & 4,74 \\
\hline
\end{tabular}

Fonte: Dados da Pesquisa.

As empresas ISE em relação à média do PGVA que demonstra a contribuição da empresa a sociedade por meio do pagamento de tributos conforme Brasil (2017), com exceção do ano de 2018 apresentaram médias superiores à do grupo Não - ISE nos demais anos. A maior diferença em relação aos grupos pode ser vista em 2016 onde o ISE teve uma média de 0,24 , enquanto que o Não ISE apresentou um resultado negativo de -0,70. Esse valor negativo representa que o valor adicionado distribuído pelas empresas não foi suficiente para cobrir a riqueza distribuída ao governo como demonstra o fato de algumas empresas, tais quais, Cosan, Br Malls, Gol, Kroton, Marfrig, Qualicorp e Ultrapar apresentarem números negativos quanto a distribuição ao governo.

A mediana das empresas ISE foi superior ao longo dos anos estudados em relação as empresas Não - ISE, com exceção do ano de 2015. Em ambos os grupos ocorreram variações, contudo as empresas ISE apresentaram uma variação maior em relação as empresas pertencentes ao grupo Não - ISE, obtendo a melhor mediana de 0,21 nos anos de 2016 e 2017 e também a pior mediana de 0,08 em 2015, que foi o único ano em que as empresas Não ISE foram melhores em relação as ISE apresentando 0,14.

Em relação a variância e o desvio padrão, nos anos de 2014,2015 e 2016 as empresas de ambos os grupos apresentaram um aumento gradual, tendo as empresas ISE apresentado seu melhor resultado 0,07 quanto a variância no ano de 2016 e o no que se refere ao desvio padrão 0,26 em 2016, enquanto as Não - ISE apresentaram 20,97 em 2016 no que se refere a variância e 4,58 em 2016 quanto ao desvio padrão, sendo esses os melhores resultados dos cincos anos. Posteriormente nos anos de 2017 e 2018 ambos os grupos tiveram decréscimo em relação aos três primeiros anos iniciais, contudo mantiveram seus números em um crescente. As empresas Não - ISE em ambas as estatísticas analisadas obtiveram valores superiores às do grupo ISE durante os cinco anos.

Os menores mínimos foram apresentados pelo grupo Não - ISE durante os anos estudados, sendo que em 2018 tanto o grupo ISE quanto o grupo Não - ISE apresentou -0,04 em relação ao mínimo. O resultado mais expressivo foi do grupo Não - ISE que apresentou 24,92 em 2016 por conta da empresa Azul que apresentou - $\mathrm{R} \$ 2.875,00$ de valor adicionado a distribuir por conta de prejuízos acumulados no período e $\mathrm{R} \$ 71.653$ distribuído ao governo. Enquanto os maiores máximos com exceção dos anos de 2014 e 2016, pertencem ao grupo Não - ISE. No quesito valores o menor mínimo foi - 24,92 no ano de 2016 e o maior máximo foi 2,59 no ano de 2018 ambos pertencentes ao grupo Não - ISE.

A amplitude das empresas Não - ISE foi maior que as das empresas ISE, em todos os anos estudados, sendo a maior amplitude $25,50 \mathrm{em} 2016$. A melhor assimetria foi apresentada pelo grupo Não - ISE 4,74 em 2018, como também os piores valores, obtendo assimetrias negativas -2,02 em 2014 e -5,46 em 2016.

A seguir a Tabela 4 detalha o indicador grau de retenção do valor adicionado:

Tabela 4 - Estatística Descritiva do GRVA

\begin{tabular}{|c|c|c|c|c|c|c|c|c|c|}
\hline Ano & Grupo & Média & Mediana & Variância & $\begin{array}{l}\text { Desvio } \\
\text { Padrão }\end{array}$ & Mínimo & Máximo & Amplitude & Assimetria \\
\hline \multirow[t]{2}{*}{2014} & ISE & 0,26 & 0,19 & 0,04 & 0,24 & $-0,12$ & 0,75 & 0,87 & 0,43 \\
\hline & $\begin{array}{l}\text { NÃO - } \\
\text { ISE }\end{array}$ & 0,34 & 0,14 & 0,05 & 1,35 & $-1,49$ & 7,01 & 8,50 & 4,32 \\
\hline \multirow[t]{2}{*}{2015} & ISE & 0,21 & 0,11 & 0,06 & 0,28 & $-0,40$ & 0,77 & 1,17 & 0,13 \\
\hline & $\mathrm{NA \tilde {O }}-$ & 0,32 & 0,06 & 0,09 & 2,56 & $-6,86$ & 11,88 & 18,73 & 2,59 \\
\hline
\end{tabular}


Sousa e Faria (2018)

Demonstração do Valor Adicionado (DVA): Uma Análise da Geração e Distribuição de Riquezas das Empresas Listadas no Índice de Sustentabilidade Empresarial (ISE)-B3

\begin{tabular}{|c|c|c|c|c|c|c|c|c|c|}
\hline Ano & Grupo & Média & Mediana & Variância & $\begin{array}{l}\text { Desvio } \\
\text { Padrão }\end{array}$ & Mínimo & Máximo & Amplitude & Assimetria \\
\hline & ISE & & & & & & & & \\
\hline \multirow[t]{2}{*}{2016} & ISE & 0,24 & 0,11 & 0,07 & 0,65 & $-0,87$ & 3,27 & 4,13 & 3,45 \\
\hline & $\begin{array}{c}\text { NÃO - } \\
\text { ISE }\end{array}$ & 1,65 & 0,17 & 20,97 & 8,00 & $-1,23$ & 43,94 & 45,17 & 5,45 \\
\hline \multirow[t]{2}{*}{2017} & ISE & 0,22 & 0,14 & 0,04 & 0,25 & $-0,26$ & 0,76 & 1,02 & 0,52 \\
\hline & $\begin{array}{c}\mathrm{NA} \mathrm{AO}- \\
\mathrm{ISE}\end{array}$ & $-0,13$ & 0,07 & 0,17 & 1,17 & $-4,74$ & 1,02 & 5,77 & $-2,93$ \\
\hline \multirow[t]{2}{*}{2018} & ISE & 0,23 & 0,14 & 0,05 & 0,26 & $-0,31$ & 0,67 & 0,98 & 0,29 \\
\hline & $\begin{array}{c}\text { NÃO - } \\
\text { ISE }\end{array}$ & 0,37 & 0,22 & 0,22 & 0,82 & $-1,59$ & 3,93 & 5,52 & 2,51 \\
\hline
\end{tabular}

Fonte: Dados da Pesquisa.

As empresas Não - ISE com relação à média do GRVA, grau de retenção do valor adicionado, que mostra quanto do valor adicionado ficou retido na empresa, na forma de lucros e/ou prejuízos acumulados, com exceção do ano de 2017 apresentaram médias superiores à do grupo ISE nos demais anos. A maior diferença em relação aos grupos pode ser vista em 2016 onde o ISE teve uma média de 0,24, enquanto que o Não- ISE apresentou um resultado de 1,65, sendo este o maior valor dentre as médias apresentadas nos anos estudados. A média negativa -0,13 apresentada no ano de 2017 significa que as empresas do grupo Não ISE tiveram prejuízo e/ou o valor adicionado obtido não foi suficiente para cobrir à riqueza distribuída para pessoal, governo e financiadores. As empresas $\mathrm{Br}$ Malls, Marfrig, BRF, Cyrela, Realt, Eletrobras e Gerdau apresentaram prejuízo retido nesse período.

A mediana das empresas ISE foi superior nos anos de 2014, 2015 e 2017 e inferior as empresas Não - ISE em 2016 e 2018. As empresas Não - ISE apresentaram uma variação maior em relação as empresas pertencentes a carteira do ISE, obtendo a melhor mediana 0,22 em 2018 dentre todas as empresas analisadas e também a pior mediana de 0,06 em 2015.

Quanto a variância e o desvio padrão, nos anos de 2014, 2015 e 2016 as empresas ISE e Não ISE obtiveram um crescimento, tendo o grupo ISE apresentado seu melhor resultado 0,07 quanto a variância no ano de 2016 e o no que se refere ao desvio padrão 0,65 em 2016, enquanto as Não - ISE apresentaram 20,97 em 2016 no que se refere a variância e 8,00 em 2016 quanto ao desvio padrão, sendo esses os melhores resultados dos anos estudados. Nos anos de 2017 e 2018 ambos os grupos tiveram decréscimo em relação aos três primeiros anos iniciais, contudo o grupo ISE manteve seus números em um crescente tanto na variância quanto no desvio padrão, enquanto que o grupo Não - ISE nesses dois últimos anos analisados teve um aumento na variância e manteve o decréscimo no desvio padrão. Nos cinco anos estudados apesar das variações ocorridas, as empresas Não - ISE em ambas as estatísticas analisadas obtiveram valores superiores às do grupo ISE.

Os menores mínimos foram apresentados pelas empresas Não - ISE durante os cinco anos analisados, sendo o menor valor o de $-6,86$ no ano de 2015 , por conta das empresas Azul, Eletrobras, Gol, Magazine Luiza, Marfrig, Rumo S.A, Suzano S.A, e Usiminas que apresentaram prejuízo acumulado no período. No quesito máximo o grupo Não - ISE apresentou superioridade em relação as empresas ISE ao longo dos cinco anos estudados, sendo o maior máximo 43,94 em 2016.

Em relação a amplitude o maior valor apresentado foi 45,17 em 2016 pelo grupo NãoISE, que obteve melhores amplitudes nos cinco anos analisados em comparação ao grupo ISE que teve a menor amplitude 0,87 em 2014. A melhor assimetria foi 5,45 em 2016 das empresas Não - ISE, assim como o pior valor -2,93 em 2017. Com exceção de 2017 as melhores assimetrias pertencem ao grupo Não - ISE. 
Sousa e Faria (2018)

Demonstração do Valor Adicionado (DVA): Uma Análise da Geração e Distribuição de Riquezas das Empresas Listadas no Índice de Sustentabilidade Empresarial (ISE)-B3

Em seguida, calculou-se o teste de normalidade para verificar se os resultados possuem desigualdade e existência de diferenças significativas, realizou-se teste estatístico específico Kolmogorov-Smirnov, verificou-se inicialmente a hipótese de normalidade dos dados para cada um dos grupos analisados. Os resultados encontrados foram os seguintes:

Tabela 5 - Teste de Normalidade

\begin{tabular}{|c|c|c|c|c|c|c|c|c|c|c|c|}
\hline \multirow[t]{2}{*}{ Indicador } & \multirow{2}{*}{$\begin{array}{c}\text { Kolmogorov- } \\
\text { Smirnov }\end{array}$} & \multicolumn{2}{|c|}{2014} & \multicolumn{2}{|c|}{2015} & \multicolumn{2}{|c|}{2016} & \multicolumn{2}{|c|}{2017} & \multicolumn{2}{|c|}{2018} \\
\hline & & ISE & $\begin{array}{c}\text { NÃO } \\
\text { ISE }\end{array}$ & ISE & $\begin{array}{c}\mathrm{NA} \tilde{\mathrm{AO}} \\
\mathrm{ISE}\end{array}$ & ISE & $\begin{array}{c}\mathrm{NA} \tilde{\mathrm{O}} \\
\mathrm{ISE}\end{array}$ & ISE & $\begin{array}{c}\text { NÃO } \\
\text { ISE }\end{array}$ & ISE & $\begin{array}{l}\text { NÃO } \\
\text { ISE }\end{array}$ \\
\hline \multirow[t]{3}{*}{ PEVA } & Estatística & , 178 &, 259 & ,228 & ,225 & 0,231 &, 326 & ,191 &, 175 & ,201 & ,237 \\
\hline & Gl & 30 & 30 & 30 & 30 & 30 & 30 & 30 & 30 & 30 & 30 \\
\hline & Sig. &, 016 &, 000 & ,000 & ,000 &, 000 &, 000 & ,007 & ,019 & ,003 & ,000 \\
\hline \multirow[t]{3}{*}{ PGVA } & Estatística &, 150 & , 194 &, 172 & ,206 & ,148 & ,496 &, 151 & ,265 &, 151 & ,287 \\
\hline & Gl & 30 & 30 & 30 & 30 & 30 & 30 & 30 & 30 & 30 & 30 \\
\hline & Sig. &, 082 & ,005 & ,023 & ,002 & ,091 & ,000 & ,077 &, 000 & ,081 & ,000 \\
\hline \multirow[t]{3}{*}{ GRVA } & Estatística & 138 &, 325 &, 176 &, 369 & ,257 & ,500 & ,197 &, 323 &, 160 &, 260 \\
\hline & Gl & 30 & 30 & 30 & 30 & 30 & 30 & 30 & 30 & 30 & 30 \\
\hline & Sig. & ,148 & ,000 & ,018 & ,000 & ,000 & ,000 & ,004 & ,000 & ,049 & ,000 \\
\hline
\end{tabular}

Fonte: Dados da pesquisa.

O indicador de Participação do Governo no Valor Adicionado das empresas ISE nos anos de 2014, 2016, 2017 e 2018 e das empresas Não - ISE em 2014 apresentaram normalidade na sua distribuição pois obtiveram significância acima de 0,05 , assim como o Grau de Retenção do Valor Adicionado das empresas ISE em 2014 por isso foram analisados com base no teste $t$ para amostras independentes, como mostra a Tabela 6:

Tabela 6 - Teste t para amostras independente

\begin{tabular}{c|c|c|c|c}
\hline \multirow{2}{*}{ Indicador } & Ano & T & Df & $\begin{array}{c}\text { Sig. (2 } \\
\text { extremidades) }\end{array}$ \\
\hline \multirow{3}{*}{ PGVA } & ISE 2014 & 1,040 & 28 &, 307 \\
\cline { 2 - 5 } & $\begin{array}{c}\text { NÃO ISE } \\
2014\end{array}$ &,- 663 & 28 &, 512 \\
\cline { 2 - 5 } & ISE 2016 &, 923 & 28 &, 364 \\
\cline { 2 - 5 } & ISE 2017 & 1,116 & 28 &, 236 \\
\cline { 2 - 5 } & ISE 2018 &, 982 & 28 &, 335 \\
\hline GRVA & ISE 2014 &,- 814 & 28 &, 423 \\
\hline
\end{tabular}

Fonte: Dados da pesquisa

As variáveis não foram significantes pois o p-value foi superior a $0,05 \mathrm{em}$ todos os casos, o que demonstra que não houve diferença significativa na média desses indicadores no período estudado. As empresas que participavam do ISE, no período analisado pela pesquisa, não apresentaram diferenças significativas com as empresas não participantes.

Os indicadores que apresentaram significância inferior a 0,05 no teste de normalidade, têm distribuição não normal e faz-se necessário a aplicação de um teste não paramétrico de Mann-Whitney, que é usado para testar se duas amostras independentes decorrem de populações com médias iguais, como uma alternativa ao teste $t$ de Student (Marôco, 2018).

Para análise do teste, considerou-se as seguintes hipóteses:

H0: $\mu$ ISE $=\mu$ Não ISE onde, as médias entre as empresas que compõem a carteira ISE e as que não compõem são iguais.

H1: $\mu$ ISE $\neq \mu$ Não ISE onde, as médias entre as empresas que compõem a carteira ISE e as que não compõem não são iguais. 
Sousa e Faria (2018)

Demonstração do Valor Adicionado (DVA): Uma Análise da Geração e Distribuição de Riquezas das Empresas Listadas no Índice de Sustentabilidade Empresarial (ISE)-B3

Admitindo-se o nível de significância $\alpha$ igual a 0,05 a Tabela 7 apresentou os seguintes resultados:

Tabela 7 - Teste de Mann - Whitney

\begin{tabular}{|c|c|c|c|c|c|c|c|c|c|c|c|}
\hline \multirow[t]{2}{*}{ Indicador } & & \multicolumn{2}{|c|}{2014} & \multicolumn{2}{|c|}{2015} & \multicolumn{2}{|c|}{2016} & \multicolumn{2}{|c|}{2017} & \multicolumn{2}{|c|}{2018} \\
\hline & & ISE & $\begin{array}{l}\text { NÃO } \\
\text { ISE }\end{array}$ & ISE & $\begin{array}{l}\text { NÃO } \\
\text { ISE }\end{array}$ & ISE & $\begin{array}{l}\text { NÃO } \\
\text { ISE }\end{array}$ & ISE & $\begin{array}{l}\text { NÃO } \\
\text { ISE }\end{array}$ & ISE & $\begin{array}{l}\text { NÃO } \\
\text { ISE }\end{array}$ \\
\hline \multirow[t]{2}{*}{ PEVA } & $\begin{array}{l}\text { U de Mann- } \\
\text { Whitney }\end{array}$ & 0,5 & 2,0 & 1,0 & 3,0 & 1,5 & 3,5 & 0,5 & 1,0 & 0,5 & 1,5 \\
\hline & P-value & ,065 & , 194 & , 129 & ,258 & ,129 & ,258 &, 065 & ,129 & ,065 & , 129 \\
\hline \multirow[t]{2}{*}{ PGVA } & $\begin{array}{c}\text { U de Mann- } \\
\text { Whitney }\end{array}$ & - & - & 7,0 & 5,0 & - & 9,0 & - & 3,0 & - & 4,0 \\
\hline & P-value & - & - & ,516 & ,387 & - & ,645 & - & ,258 & - & ,323 \\
\hline \multirow[t]{2}{*}{ GRVA } & $\begin{array}{l}\text { U de Mann- } \\
\text { Whitney }\end{array}$ & - & 5,5 & 4,5 & 9,5 & 6,0 & 6,5 & 3,5 & 8,5 & 4,0 & 4,5 \\
\hline & P-value & - & ,387 & ,323 & ,645 & ,452 & ,452 & ,258 & ,581 & ,323 & ,323 \\
\hline
\end{tabular}

Fonte: Dados da pesquisa.

Ao analisar os segmentos separadamente, apesar do $\mathrm{p}$ valor apresentar resultados diferentes em cada um, todos os indicadores de distribuição de riqueza, na estatística do teste de Mann-Whitney são maiores que o nível de significância igual a 0,05. Desta forma, pode se perceber que os grupos ISE e Não ISE não apresentam evidência estatística de que possuem médias diferentes nos seus respectivos segmentos.

\section{CONCLUSÃO}

A contribuição do ISE (Índice de Sustentabilidade Empresarial) como uma variável para analisar o desempenho e a rentabilidade das empresas é importante para os estudos na área de sustentabilidade e tem obtido crescimento no meio acadêmico, estimulando a utilização de políticas mais sustentáveis para a sociedade.

Este trabalho buscou por meio de estatísticas descritivas, testes estatísticos e análises, evidenciar as diferenças entre empresas que compõem ou não a carteira ISE no período de 2014 a 2018. Para isso foram estudadas e analisadas 60 empresas que possuem capital aberto na bolsa de valores B3, sendo 30 empresas pertencentes a carteira ISE e outras 30 empresas não pertencentes a essa carteira.

Os resultados apresentados na estatística descritiva dos indicadores mostraram que a média dos indicadores de distribuição de riqueza das empresas ISE foram superiores no PGVA enquanto que no PEVA e GRVA as empresas Não - ISE foram superiores ao longo dos anos. A mediana das empresas ISE apresentou superioridade nos indicadores PGVA e GRVA mantendo- se em situação semelhante as Não- ISE no PEVA.

A partir dos testes estatísticos t de Student e Mann-Whitney pode-se perceber, em um intervalo de $95 \%$ de confiança, com significância de 0,05, que as empresas do Grupo ISE e Não ISE apresentam evidências estatísticas similares, ou seja, não apresentaram variação significativa em relação ao período analisado pois o $\mathrm{p}$-value foi superior a $0,05 \mathrm{em}$ todos os casos. Conclui-se assim que o fato das empresas da amostra, pertencerem ou não ao Índice de Sustentabilidade Empresarial no período analisado, não é refletido significativamente na DVA dessas empresas, considerando os indicadores utilizados na pesquisa.

O estudo limitou -se a analisar as empresas pertencentes a carteira do ISE 2018 que possui 30 empresas em comparação com outras 30 empresas listadas na B3 que não pertencem a essa carteira, o período também foi limitado entre 2014 e 2018. Como sugestão a pesquisas futuras, têm-se a utilização de outros indicadores de DVA presentes na literatura 
Demonstração do Valor Adicionado (DVA): Uma Análise da Geração e Distribuição de Riquezas das Empresas Listadas no Índice de Sustentabilidade Empresarial (ISE)-B3

contábil, assim como realizar outros testes para verificar a variância e a significância dos indicadores. Outra sugestão é abordar essa temática em um estudo de caso, analisando com maior profundidade os indicadores apresentados nesse estudo.

\section{REFERÊNCIAS}

BARROS, C. M. E.; ISIDORO, C.; CATAPAN, A.; SCHERER, L.M. Relevância do valor adicionado: um estudo empírico em sociedades anônimas abertas brasileiras. Anais do XXXII Encontro Nacional de Engenharia de Produção, Bento Gonçalves, RS, Brasil, p. 1-15, 15 out. 2012. Disponível em: <

http://www.abepro.org.br/biblioteca/enegep2012_TN_STP_159_929_19761.pdf $>$. Acesso em: 16 mar. 2018.

BEUREN, I. M. Como elaborar trabalhos monográficos em contabilidade: teoria e pratica. 3. ed. São Paulo: Atlas, 2006.

BRASIL, M. M. A informação da carga tributária das empresas listadas na BM\&FBOVESPA a partir da DVA. 2017. Trabalho de conclusão de curso (Grau de bacharel em Ciências Contábeis) - Unijuí, Ijuí, 2017. Disponível em:< http://bibliodigital.unijui.edu.br:8080/xmlui/bitstream/handle/123456789/4808/Mariana\%20 Moura\%20Brasil.pdf?sequence=1 >. Acesso em: 22 mar. 2018.

COMITÊ DE PRONUNCIAMENTOS CONTÁBEIS. Pronunciamento Técnico. CPC 09: Demonstração do Valor Adicionado. Brasília, DF, 30 out. 2008. Disponível em:< http://www.cpc.org.br/CPC/DocumentosEmitidos/Pronunciamentos/Pronunciamento?Id=40>. Acesso em: 12 jan. 2018.

COMITÊ DE PRONUNCIAMENTOS CONTÁBEIS. Pronunciamento Técnico. CPC 00: Estrutura Conceitual para Elaboração e Divulgação de Relatório Contábil-Financeiro. Brasília, DF, 02 dez . 2011. Disponível em: $<$ http://www.cpc.org.br/CPC/DocumentosEmitidos/Pronunciamentos/Pronunciamento?Id=80>. Acesso em 12 jan.2018

CUNHA, J. V. A. Demonstração contábil do valor adicionado - DVA - um instrumento de mensuração da distribuição da riqueza das empresas para os funcionários. 2002. Dissertação (Mestrado em Controladoria e Contabilidade) - Faculdade de Economia e Contabilidade da Universidade de São Paulo, São Paulo. Disponível em : < http://www.scielo.br/pdf/rcf/v16n37/v16n37a01.pdf >. Acesso em 16 mar.2018

DE LUCA, M. M. M. Demonstração do valor adicionado: do cálculo da riqueza criada pela empresa ao valor do PIB. São Paulo: Atlas, 1998.

GERHARDT, T. E.; SILVEIRA, D T. Métodos de Pesquisa. Rio Grande do Sul: Editora da UFRGS, 2009. Disponível em: < http://www.ufrgs.br/cursopgdr/downloadsSerie/derad005.pdf >. Acesso em: 11 jan. 2018.

GIDDENS, A. Sociologia.Tradução: Sandra Regina Netz. 6 ed. Porto Alegre: Artmed, 2012. GIL, A. C. Como elaborar projetos de pesquisa. 4. ed. São Paulo: Atlas, 2002.

Índice de Sustentabilidade Empresarial. ISE. Disponível em: < http://www.b3.com.br/pt_br/market-data-e-indices/indices/indices-de-sustentabilidade/indicede-sustentabilidade-empresarial-ise.htm >. Acesso em: 15/12/2018. 
Demonstração do Valor Adicionado (DVA): Uma Análise da Geração e Distribuição de Riquezas das Empresas Listadas no Índice de Sustentabilidade Empresarial (ISE)-B3

IUDÍCIBUS, S.; MARTINS, E.; GELBCKE, E. R.; SANTOS, A. Manual de Contabilidade Societária. 2 ed., São Paulo: Atlas, 2013.

MACHADO, M. A. V.; MACEDO, M. A.S.; MACHADO, M. R. Análise da Relevância do Conteúdo Informacional da DVA no Mercado Brasileiro de Capitais. Revista Contabilidade \& Finanças, - USP, São Paulo, v. 26, n. 67, p. 57-69, 2015. Disponível em:< http://www.scielo.br/pdf/rcf/v26n67/pt_1519-7077-rcf-26-67-00057.pdf >. Acesso em: 16 Mai. 2018.

MARION, J. C. Análise das Demonstrações Contábeis: Contabilidade Empresarial. 5. ed. São Paulo: Atlas, 2010.

MARIN, D. A Demonstração do Valor Adicionado em Empresas do Novo Mercado: uma análise da distribuição da riqueza aos agentes econômicos. 2017. Trabalho de Conclusão de Curso (Grau de Bacharel em Ciências Contábeis) - Universidade Caxias do Sul, Caxias do Sul, 2017. Disponível em:< https://repositorio.ucs.br/xmlui/bitstream/handle/11338/3197/TCC\%20Daiane\%20Marin.pdf? sequence $=1 \&$ is Allowed=y $>$. Acesso em: 28 mar. 2018.

MARQUES, A. V.C.; SANTOS, C. K. S.; LEMES, S. Divulgação dos Relatórios Contábeis: um estudo da relevância das informações contábeis sobre ativos intangíveis. Anais do Encontro da Associação Nacional de Pós-Graduação e Pesquisa em Administração, Rio de Janeiro, RJ, Brasil, p. 1-16, 13 set. 2014. Disponível em:< http://www.anpad.org.br/admin/pdf/2014_EnANPAD_CON890.pdf $>$. Acesso em: 16 set. 2018.

MARÔCO, J. Análise Estatística com o SPSS Statistics. 7. ed. Portugual: ReportNumber, 2018. Disponível em: $<$ https://books.google.com.br/books?hl=pt-

BR\&lr=\&id=Ki5gDwAAQBAJ\&oi=fnd $\& p g=P P 1 \& d q=$ teste + parametrico $+e+n \% C 3 \% \mathrm{~A} 3 \mathrm{o}+\mathrm{p}$ aram\%C3\%A9trico\&ots=zMurqxGegH\&sig=dJ0YzZUNKz_AuDuuxxeMt7zqjFs\#v=onepag e\&q\&f=true> . Acesso em : 16 jun.2018.

MONTOTO, E. Contabilidade Geral e Avançada.5.ed. São Paulo: Saraiva, 2018.1561p. Disponível em: $<$ https://georgenunes.files.wordpress.com/2018/11/contabilidade-geral-eavanc3a7ada-eugenio-montoto-2018.pdf > . Acesso em: 10 Mai.2018.

NUNES, V. M.; MIRANDA, G. J. Geração e Distribuição do Valor Adicionado em 2013: análise das companhias listadas no IBrX-100, Revista Evidenciação Contábil e Finanças, v.4, n. 1, p. 18-32, jan/abr 2016. Disponível em: <

https://periodicos.ufpb.br/index.php/recfin/article/view/24844/0>. Acesso em: 18 jun. 2018.

OLIVEIRA, I.A. F.; COELHO, A. C.D. Impacto da divulgação obrigatória da DVA:

Evidência em indicadores financeiros. Revista Evidenciação Contábil \& Finanças, João Pessoa, v. 2, n. 3, p. 41-55, set/dez. 2014. Disponível em : < https://www.researchgate.net/publication/269464822_Impacto_da_Divulgacao_Obrigatoria_d a_DVA_Evidencia_em_Indicadores_Financeiros>. Acesso em: 14 fev.2018.

OLIVEIRA, M. S.; RECH, I. J.; CUNHA, M. F. Relação Entre a Distribuição de Riqueza Apresentada na DVA e o IDH-M dos Municípios Sede de Empresas Abertas. Anais do congresso USP : Contabilidade e Controladoria no Século XXI, 2015, São Paulo. São Paulo: [s. n.], 2015. Disponível em: < https://congressousp.fipecafi.org/anais/artigos152015/289.pdf >. Acesso em: 14 fev. 2018. 
Demonstração do Valor Adicionado (DVA): Uma Análise da Geração e Distribuição de Riquezas das Empresas Listadas no Índice de Sustentabilidade Empresarial (ISE)-B3

QUINTANA, A. C.; MARTINS, A. S. R.; JACQUES, F. V. S.; MACHADO, D. Pias. O balanço social como um instrumento de informação para a sociedade: um estudo na Universidade Federal do Rio Grande. Revista Contemporânea de Contabilidade, v. 10, n. 19, p. 49-70, 2013. ISSN 2175-8069. Disponível em : < file:///C:/Users/User/Downloads/Martins_Quintana_Jacques_Machado_2013_O-balancosocial-como-um-instr_35492.pdf>. Acesso em: 24 jan.2018.

RODRIGUES, J. M.; ELIAS, W. G.; CAMPOS, E. S. Relevância da Informação Contábil: uma análise dos efeitos da contabilização dos gastos com pesquisa e desenvolvimento com a aplicação da Lei 11.638/07 no mercado brasileiro. Anais do XIV Congresso USP de Controladoria e Finanças, São Paulo, SP, Brasil, 21 jul. 2014. Disponível em:< https://congressousp.fipecafi.org/anais/artigos142014/237.pdf >. Acesso em: 16 mai. 2018.

SILVA, A. C. R. Metodologia da pesquisa aplicada a contabilidade: orientações de estudos, projetos, artigos, relatórios, monografias, dissertações, teses. São Paulo: Atlas, 2003.

SILVA, A. F. Demonstração do Valor Adicionado: as empresas classificadas como mais sustentáveis evidenciam maior distribuição de riqueza à sociedade?. Trabalho de Conclusão de Curso. Uberlândia, junho 2017. Disponível em: < http://repositorio.ufu.br/bitstream/123456789/19302/1/DemonstracaoValorAdicionado.pdf $>$. Acesso em: 17 jan. 2018. 